\title{
Dysfunction of anterior pituitary gland in women patients with recent fibromyalgia: A cross-sectional observational study
}

\author{
Marwan S.M. Al-Nimer ${ }^{1,2}$, Talar A.M. Mohammad ${ }^{3}$, Avin M.A Maroof ${ }^{4}$
}

\begin{abstract}
Objective: To assess the basal levels of circulating anterior pituitary gland hormones in women presented with a recent diagnosis of fibromyalgia (FM) Methods: This cross-sectional study was included 130 women presented with a clinical signs and symptoms of FM women and 35 age-matched healthy subjects served as controls. The plasma levels of growth hormone (GH) and adrenocorticotrophic hormone (ACTH), and the serum levels of prolactin (PRL) and thyroid stimulating hormone (TSH) were measured. The scores of the Revised Fibromyalgia Impact Questionnaire (FIQR), the number of tender points (TPs), Fatigue Severity Scale (FSS), Insomnia Severity Index (ISI), and the Hamilton's scale for depression (HSD) were measured. Results: Significantly higher levels of PRL, TSH, and ACTH and lower levels of GH were observed in FM patients. The ACTH level was inversely and significantly correlated with the number of the TPs $\left(r=-0.173, R^{2}=0.31, F=4.110, p=0.045\right)$. The positive predictive values of $G H, T H S, P R L$ and $A C T H$ were $92.3,63.8,90.8$, and $86.1 \%$, respectively.
\end{abstract}

Conclusions: Our results indicate that dysfunction of the anterior pituitary gland is a feature of FM.

Keywords: fibromyalgia, hormones, pain, fatigue, depression

\section{INTRODUCTION}

Fibromyalgia is a chronic disease of unknown etiology characterized by pain, fatigue, depression and sleep disturbances that linked to several endogenous neurotransmitters and hormones (1-3). Fibromyalgia is a member of centralized pain syndromes by which the pain perception occurred in absence of noxious stimuli (4). Centralized pain disorderar are more common in women (5), and generally associated with fatigue, insomnia, impaired memory, anxiety, and depression $(6,7)$. Dysregulation of the hypothamic-pituitary adrenal axis is commonly observed in centralized pain disorders (4).

In fibromyalgia, serum levels of adrenocorticotrophic hormone (ACTH) are within normal levels, but any increment in the ACTH levels induced improvement of the clinical symptoms (8). Moreover, when the cortisol production increased, the pain is reduced and the sleep quality is improved (9). Previous studies demonstrated an alteration in the nocturnal ACTH-adrenal signaling and inhibitory feedback mechanism were and linked the changes to the somatic symptoms (9).

Abnormal serum levels of thyroid stimulating hormone (TSH) were observed in FM patients, and a 3.5\% had higher TSH levels while $1.4 \%$ of patients had a lower serum TSH level (10). However, there is evidence that autoimmune thyroid disease is co-existed with FM as thyroid gland autoimmune antibodies were detected in FM patients $(11,12)$. There are no cumulative data about the serum levels of prolactin (PRL) and growth hormone (GH) in FM patients. As early as 2001, Gruel et al reported a significant low GH and a significant higher PRL level in a small sample of 20 patients (13). A recent study showed that the serum levels of insulin-like growth factor hormone do not show a significant difference between the women with FM and healthy subjects (14). Moreover, small doses of gamma hydroxybutyrate, a growth hormone enhancing medicine, failed to increase the level of $\mathrm{GH}$ and to improve the clinical symptoms (15). Women with FM

\footnotetext{
1 Al-Mustansiriya University, College of Medicine, Baghdad, Iraq

2 Hawler Medical University, College of Pharmacy, Erbil, Iraq

3 Department of Pharmacology and toxicology, Clinical Pharmacy Hawler Medical University, Erbil, Iraq

4 Senior Specialist in Rheumatology, Rizagary Teaching Hospital, Erbil, Iraq
}

Correspondence: Marwan S.M. Al-Nimer

Al-Mustansiriya University, College of Medicine, Baghdad, Iraq

Hawler Medical University, College of Pharmacy, Erbil, Iraq

E-mail: alnimermarwan@ymail.com

Received: 5 Feb 2018, Accepted: 22 Apr 2018

(C) 2018 by the authors; licensee Modestum Ltd., UK. This article is an open access article distributed under the terms and conditions of the Creative Commons Attribution License (http://creativecommons.org/licenses/by/4.0/). 
showed non-significant changes in the plasma PRL levels when the patients treated with tryptaphan (a precursor of serotonin), while upregulation of the plasma PRL level observed in women with chronic fatigue syndrome (16).

The rationale of this study is the clinical symptoms of fibromyalgia are related to the disturbances of the endocrine system, and to link these disturbances to each clinical feature of FM is a worth trial in understanding the pathogenesis of FM. Literature survey did not disclose any research that measured the anterior pituitary gland hormones at the time of the diagnosis of FM. Therefore, we test the hypothesis that central sensitization of pain pathways is the hallmark of pathogenesis of FM and may cause fatigue, sleep disturbances and mood flactuation leading to the pituitary gland dysfunction. The aim of this study is to assess the basal levels of circulating anterior pituitary hormones in women with a newly diagnosed FM, and to relate these levels to the cardinal features of FM including pain, fatigue, insomnia, and depression.

\section{PATIENTS AND METHODS}

This cross-sectional study was conducted in the Department of Pharmacology and Toxicology - Clinical Pharmacy, College of Pharmacy at Hawler Medical University in Erbil- Iraq from Jan 2017 to Dec. 2017. A consent form was obtained from each patient prior to the admission to the study. The study was conducted according to the ethical guidelines constructed by the Institutional Scientific Committee in which the treatment or using device should not be harmful to the patient and the patient is free to decline from the study or to refuse for study admission.

The patients were recruited from the Public Clinics and Private Clinics of Rheumatology in Baghdad-Iraq, and from the Razgary Teaching Hospital in Erbil-Iraq. The eligible patients are women aged less than 60 years old. The criteria for inclusion are new cases of fibromyalgia with signs and symptoms suggestive of fibromyalgia of at least three months of duration. The specialists in the Rheumatology and the researchers examined each patient thoroughly. The diagnosis of fibromyalgia was confirmed by the consultants of Rheumatology using the American College of Rheumatology (ACR) 10 diagnostic criteria and the Arabic version (17-19) with negative laboratory tests of rheumatic profile including erythrocyte sedimentation rate, C-reactive protein and latex rheumatoid factor. Conditions that influenced the levels of pituitary hormones were excluded. Therefore, patients with a history of hypertension, diabetes mellitus, chronic liver diseases, renal disorders, autoimmune diseases and drug intake e.g. non-steroidal anti-inflammatory drugs were excluded. The sample size of FM patients was calculated by using margin of errors ( $\alpha=0.05, \beta=0.2$ ), two tails and $95 \%$ confidence interval.

The authors examined, interviewed each participant and completed a health questionnaire included Fibromyalgia Impact Questionnaire Revised (FIQR) (20), Insomnia Severity index (ISI) (21, 22), the Hamilton's Depression Rating Scale for depression (HDRS-21) (23) and the Fatigue Severity Scale (FSS) (24). The ISI is a seven-item questionnaire and the items are scored on a five point scale with $0=$ no problem and $4=$ severe. Insomnia was defined as a total score of the SIS $\geq 10$. The FSS is a nine-item questionnaire and the items are scored on a 7 point scale with $1=$ strongly disagree and $7=$ strongly agree. The mean value of all the scores was determined. The authors assessed the pain that fulfills the following criteria: distributed in all of the body's four quadrants plus axial pain; and at minimum 11 out of 18 predefined tender points that triggered by a pressure of a maximum of $4 \mathrm{~kg} / \mathrm{cm}^{2}$ by using algometry.

Peripheral venous blood samples were drawn immediately into the tubes that containing anticoagulant (EDTA), and the others without anticoagulant. The blood samples were centrifuged at $2500 \mathrm{rpm}$ for $10 \mathrm{~min}$, and the sera and plasma were separated for determination of $\mathrm{ACTH}, \mathrm{TSH}, \mathrm{PRL}$ and $\mathrm{GH}$ using the technique of enzyme linked immunosorbent antibody (ELISA) test.

\section{Statistical Analysis}

Data are expressed as number, percent; mean \pm SD. Independent samples $-t$ - test was used to evaluate differences between the two groups. For all tests, a two-tailed $p \leq 0.05$ was considered statistically significant. The area under the curve of the serum/plasma levels of anterior pituitary hormones of Group II in respect to Group I were estimated using receiving operating characteristics as discriminating factors of FM. Simple (rho) correlation and multi-linear regression tests were used to predict the circulating levels of the hormone in reference to the clinical features and accordingly. The cutoff value, sensitivity, specificity, positive predictive value, and negative predictive value of the serum hormone level as a discriminator of FM were determined. All calculations were made using Excel 2003 and SPSS -20 programs for Windows. 
Table 1: Background data of the participants

\begin{tabular}{|c|c|c|c|}
\hline Variables & Group I $(n=35)$ & Group II $(n=130)$ & $\boldsymbol{P}$ \\
\hline Age (year) & $42.7 \pm 7.7$ & $41.5 \pm 7.6$ & 0.410 \\
\hline Current moking & $8(22.9)$ & 17(13.1) & 0.152 \\
\hline \multicolumn{4}{|l|}{ Residency } \\
\hline Rural & $8(22.9)$ & $9(6.9)$ & 0.006 \\
\hline Urban & $27(77.1)$ & 91(93.1) & 0.006 \\
\hline Body mass index $\left(\mathrm{kg} / \mathrm{m}^{2}\right)$ & $25.2 \pm 1.2$ & $25.9 \pm 2.5$ & 0.111 \\
\hline Total symptoms score of FIQR $(0-100)$ & $24.8 \pm 3.5$ & $64.2 \pm 4.8$ & $<0.001$ \\
\hline Tender points $(0-18)$ & $4.9 \pm 1.4$ & $14.3 \pm 1.7$ & $<0.001$ \\
\hline Mean score of fatigue severity scale $(0-90)$ & $2.25 \pm 0.21$ & $4.4 \pm 0.3$ & $<0.001$ \\
\hline Total Insomnia score & $5.6 \pm 1.3$ & $19.0 \pm 2.0$ & $<0.001$ \\
\hline Total Hamilton Depression score & $11.0 \pm 2.9$ & $25.9 \pm 5.0$ & $<0.001$ \\
\hline
\end{tabular}

The results are expressed as number (percentage), mean \pm SD. $P$ value is calculated by using unpaired two tailed Student ' $t$ ' test and the difference between percentage test between Group I (healthy subjects) and Group II (fibromyalgia patients). FIQR: fibromyalgia impact questionnaire revised.

Table 2: Baseline levels of morning anterior pituitary hormones

\begin{tabular}{lccc}
\hline Variables & Group I $(\mathbf{n}=\mathbf{3 5})$ & Group II $(\mathbf{n = 1 3 0})$ & $\boldsymbol{P}$ \\
\hline Serum thyroid stimulating hormone $(\mathrm{mU} / \mathrm{L})$ & $2.84 \pm 0.59$ & $3.33 \pm 0.42$ & $<0.001$ \\
Serum prolactin $(\mathrm{ng} / \mathrm{ml})$ & $8.64 \pm 2.14$ & $14.11 \pm 2.49$ & $<0.001$ \\
Plasma adrenocorticotrophic hormone $(\mathrm{pg} / \mathrm{ml})$ & $14.3 \pm 2.75$ & $16.78 \pm 3.21$ & $<0.001$ \\
Plasma growth hormone $(\mathrm{pmol} / \mathrm{L})$ & $398.6 \pm 30.9$ & $309.3 \pm 44.5$ & $<0.001$ \\
\hline
\end{tabular}

The results are expressed as mean \pm SD. $P$ value is calculated by using unpaired two tailed Student ' $t$ ' test between Group I (healthy subjects) and Group II (fibromyalgia patients).

Table 3: Correlations between the serum/plasma levels of pituitary hormones with the clinical features of fibromyalgia

\begin{tabular}{|c|c|c|c|c|c|c|c|c|}
\hline \multirow[t]{2}{*}{ Pituitary hormones } & \multicolumn{2}{|c|}{ Tender points number } & \multicolumn{2}{|c|}{ Fatigue severity scale } & \multicolumn{2}{|c|}{$\begin{array}{c}\text { Insomnia severity } \\
\text { index }\end{array}$} & \multicolumn{2}{|c|}{$\begin{array}{c}\text { Hamilton's depression } \\
\text { rating scale }\end{array}$} \\
\hline & $r$ & $P$ & $\mathrm{r}$ & $P$ & $r$ & $P$ & $r$ & $P$ \\
\hline Serum thyroid stimulating hormone $(\mathrm{mU} / \mathrm{L})$ & -0.153 & 0.082 & -0.063 & 0.473 & 0.171 & 0.052 & 0.052 & 0.574 \\
\hline Serum prolactin $(\mathrm{ng} / \mathrm{ml})$ & -0.014 & 0.872 & -0.022 & 0.802 & -0.077 & 0.386 & -0.084 & 0.344 \\
\hline Plasma adrenocorticotrophic hormone (pg/ml) & -0.176 & 0.045 & -0.094 & 0.287 & -0.141 & 0.109 & 0.126 & 0.153 \\
\hline Plasma growth hormone (pmol/L) & 0.065 & 0.461 & 0.033 & 0.709 & 0.111 & 0.209 & 0.068 & 0.444 \\
\hline
\end{tabular}

The results are expressed as correlation factor $(r)$ and probability $(P)$ value

\section{RESULTS}

A total number of 35 age-matched healthy women served as a control (Group I) and 130 women patients (Group II) diagnosed as recent onset fibromyalgia were included in this study.

Baseline characteristic features of the Group II did not differ significantly from corresponding characteristics of Group I (Table 1). The clinical symptoms that associated with fibromyalgia showed significantly higher scores including the total symptoms of FIQR, tender points, fatigue insomnia and depression related symptoms (Table 1). Significant higher levels of TSH, PRL, and ACTH hormones were observed in Group II, which reached to $17.3 \%, 6.3 \%$, and $20 \%$ of the Group I levels (Table 2). Plasma GH level was decreased significantly to $309.3 \pm 44.5 \mathrm{pmol} / \mathrm{L}$ compared to $398.6 \pm 30.6 \mathrm{pmol} / \mathrm{L}$ in the Group I (Table 2). Group II patients showed that the area under the curve of the plasma GH was significantly lower than 0.5 whereas the area under the curve of the TSH, PRL, ACTH were significantly higher than 0.5 (Figure 1). There were no significant correlations between GH or TSH or PRL with FIQR, TPs, FSS, ISI, HSD, while the ACTH was inversely and significantly correlated with the number of the TPs (Table 3). Figure 2 showed that the significant correlation between tender points number and the plasma ACT level can be predicted in $31 \%$ of patients $\left(R^{2}=0.31, F=4.110\right.$, $p=0.045$ ). The cutoff value, sensitivity, specificity, positive predictive value, and negative predictive value of each hormone are presented in Figure 1. 


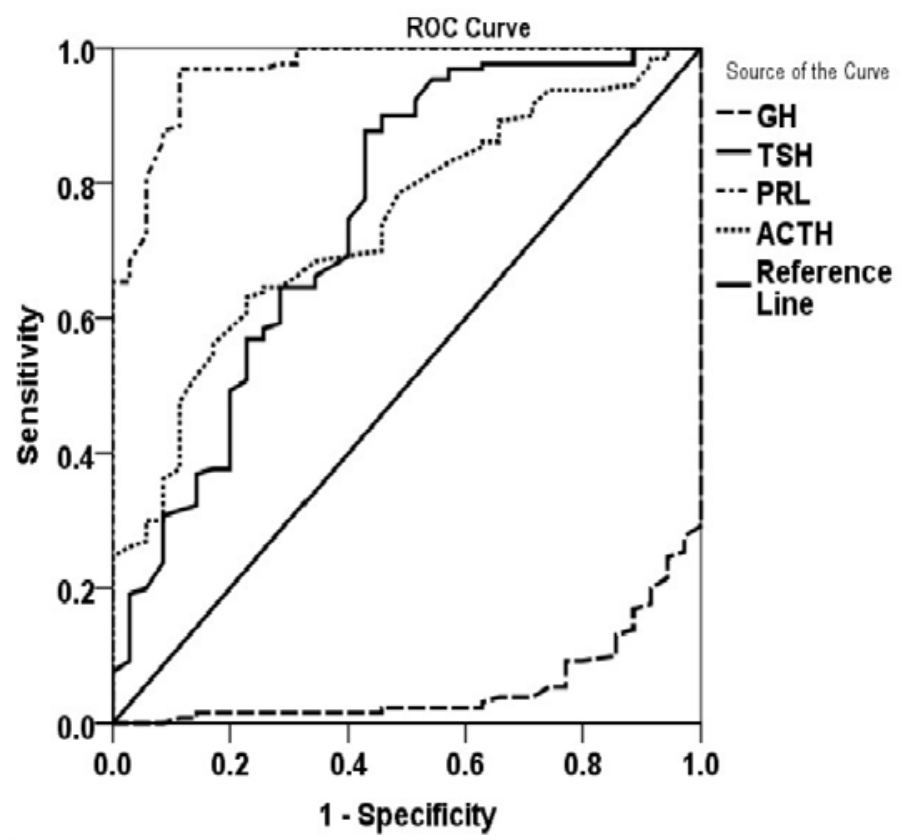

\begin{tabular}{|l|l|l|l|l|l|l|l|}
\hline Homones & $\begin{array}{l}\text { Cutoff } \\
\text { value }\end{array}$ & sensitivity & specificity & PPV & NPV & $\begin{array}{l}\text { Area under the } \\
\text { curve (95\% } \\
\text { Confidence } \\
\text { interval) }\end{array}$ & Probability \\
\hline GH (pmol/L) & 380 & 93.8 & 73.0 & 92.3 & 77.1 & $0.053(0.200-0.087)$ & $<0.001$ \\
\hline TSH (mU/L) & 3.2 & 89.3 & 34.7 & 63.8 & 71.4 & $0.750(0.650-0.850)$ & $<0.001$ \\
\hline PRL (ng/ml) & 11.0 & 96.7 & 72.1 & 90.8 & 88.6 & $0.968(0.939-0.996)$ & $<0.001$ \\
\hline ACTH $((\mathrm{pg} / \mathrm{ml})$ & 13.5 & 90.4 & 56.1 & 86.1 & 65.7 & $0.739(0.654-0.924)$ & $<0.001$ \\
\hline
\end{tabular}

Figure 1: Area under the curve of the circulating anterior pituitary hormones in women presented with newly diagnosis of fibromyalgia (Group II). GH: growth hormone, TSH: Thyroid stimulating hormone, PRL: Prolactin hormone, ACTH: Adrenocorticotrophic hormone. PPV: positive predictive value, NPV: Negative predictive value

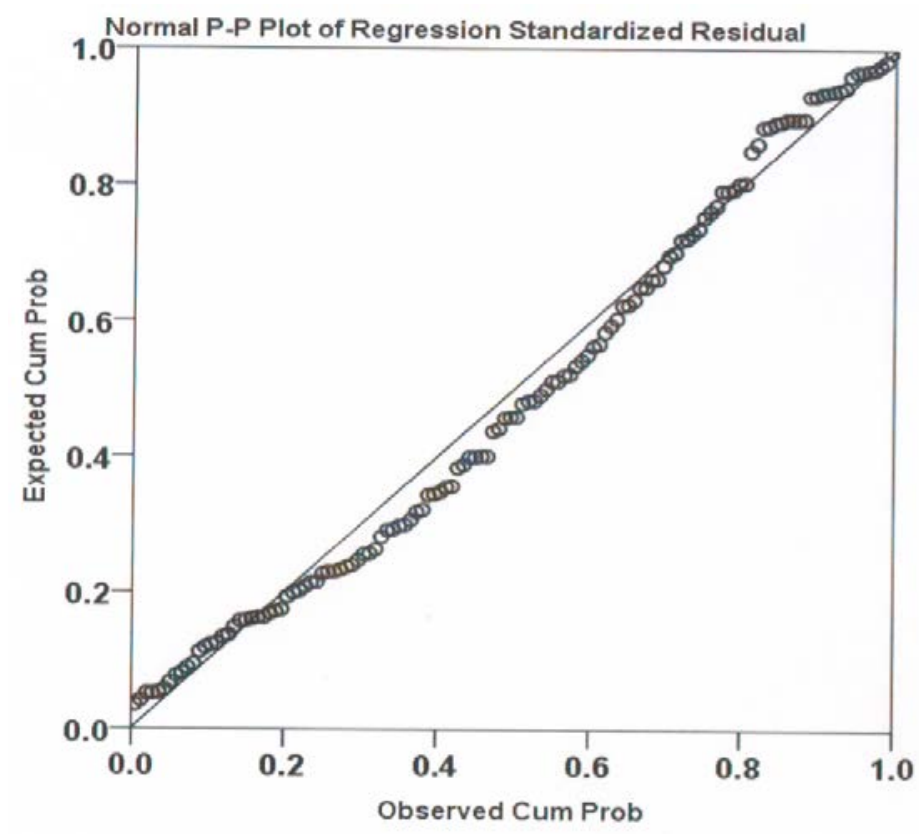

Figure 2: Regression of the adrenocorticotrophic hormone (as dependent variable) with the tender points number (as independent variable). $R=-0.176, R^{2}=0.031, F=4.11, p=0.045, \beta$-coefficient of $A C T H=21.491$ and the $\beta$-coefficient of the tender points number $=0.331$ 


\section{DISCUSSION}

The results of this study show that there are significant changes in the levels of the circulating hormones in patients with fibromyalgia suggestive a dysfunction of an anterior pituitary gland. Although the circulating levels of these hormones are within the normal range, they significantly differ from the corresponding values of healthy subjects (Group I). There is evidence that the pain perception of fibromyalgia is associated with alteration in the circadian rhythm of the $\mathrm{GH}$ release and this reflected on its serum level (25). Low levels of GH that observed in this study may be the cause or the outcome of fibromyalgia as there is evidence that using low doses of $\mathrm{GH}$ as add-on therapy is effective in reducing the pain (26). Moreover, increasing the serum level of the $\mathrm{GH}$ to high normal range could reverse many disorders, including FM (27). Therefore, GH is not a specific factor that linked with fibromyalgia, and this explained the nonsignificant correlation of the GH levels with clinical features of FM. A significantly higher level of TSH that observed in this study is in agreement with other studies and highlights to measure this hormone as a secondary measure in the diagnosis of FM (10). There is no doubt that stress induced the release of PRL hormone, and this explained the significantly high levels of serum PRL in this study. Prolactin hormone plays a role in the sensitization of the neurons and potentiates the pain response (28). Bote et al. reported that dysregulation or imbalance in the neuroendocrine function is involved in the pathogenesis of FM based on the alterations of the circulating neuroendocrine-stress biomarkers including CRF, ACTH, and insulin growth factor-1 (29). Therefore, a significant high ACTH level that reported in this study is in agreement with other studies. The inverse significant correlation between the number of tender points and the serum ACTH level indicated a physiological body response to pain by increasing the serum cortisol level and thereby a negative feedback mechanism of ACTH secretion. In general, significant high TSH, PRL, and ACTH levels associated with chronic stress which is a manifestation of fibromyalgia (30). The most important finding in this study is the significant inverse correlation between the ACTH hormone level with the number of the tender points, and it can consider as a significant predictor in $31 \%$ of FM patients. Previous studies found that there is an association between serum cortisol level and the fatigue symptom as this study confirmed the significant high score of FSS is associated with high ACTH level (31). A low serum cortisol level in FM that reported by other authors and the higher plasma levels of ACTH that found in this study indicates that there is a dysregulation of the hypothalamic pituitary adrenal axis (32). The strength of this study is attributed to the measurements of four hormones simultaneously in women presented with recent onset of fibromyalgia. Fibromyalgia induced changes in the levels of pituitary hormones because our patients did not use any medicine that interferes with the pituitary gland hormones. Therefore, the plasma level of ACTH can serve as a discriminating test of FM (the specificity is $77 \%$ ), and as a predictor in the assessment of pain in FM. Limitations of the study included that the assessment of diurnal rhythm of the hormones secretion did not carry on as well as the sex hormones levels were not determined.

We conclude that dysfunction of the anterior pituitary gland is a feature of FM and measurement of ACTH is recommended as an aid in the diagnosis of FM and as a predictor of pain severity.

\section{ACKNOWLEDGEMENT}

The authors express their thanks to the assistant lecturer Sara M. Ali for her effort in checking the editing proof of this article.

\section{REFERENCES}

1. Ohara N, Katada S, Yamada T, Mezaki N, Suzuki H, Suzuki A, et al. Fibromyalgia in a patient with cushing's disease accompanied by central hypothyroidism. Intern Med. 2016;55(21):3185-90. PubMed PMID: 27803417. https://doi.org/10.2169/internalmedicine.55.5926

2. Schertzinger $M$, Wesson-Sides $K$, Parkitny $L$, Younger J. Daily fluctuations of progesterone and testosterone are associated with fibromyalgia pain severity. J Pain. 2017 Dec 14. pii: S1526-5900(17)30804-0, PubMed PMID: 29248511. https://doi.org/10.1016/j.jpain.2017.11.013

3. Doerr JM, Fischer S, Nater UM, Strahler J. Influence of stress systems and physical activity on different dimensions of fatigue in female fibromyalgia patients. J Psychosom Res. 2017 Feb;93:55-61. PubMed PMID: 28107893. https://doi.org/10.1016/j.jpsychores.2016.12.005

4. Eller-Smith OC, Nicol AL, Christianson JA. Potential mechanisms underlying centralized pain and emerging therapeutic interventions. Front Cell Neurosci. 2018 Feb 13;12:35. eCollection 2018. Pubmed PMID: 29487504. https://doi.org/10.3389/fncel.2018.00035 
5. Vincent A, Lahr BD, Wolfe F, Clauw DJ, Whipple MO, Oh TH, et al. Prevalence of fibromyalgia: a population-based study in Olmsted County, Minnesota, utilizing the Rochester Epidemiology Project. Arthritis Care Res (Hoboken). 2013 May;65(5):786-92. Pubmed PMID: 23203795. https://doi.org/10.1002/acr.21896

6. Nickel JC, Tripp DA, Pontari M, Moldwin R, Mayer R, Carr LK, et al. Psychosocial phenotyping in women with interstitial cystitis/painful bladder syndrome: a case control study. J Urol. 2010 Jan;183(1):167-72. PMID: 19913812. https://doi.org/10.1016/j.juro.2009.08.133

7. Bullones Rodríguez MÁ, Afari N, Buchwald DS; National Institute of Diabetes and Digestive and Kidney Diseases Working Group on Urological Chronic Pelvic Pain. Evidence for overlap between urological and nonurological unexplained clinical conditions. J Urol. 2013 Jan;189(1 Suppl):66-74. $\quad$ PMID: 23234637. https://doi.org/10.1016/j.juro.2012.11.019

8. Genc A, Tur BS, Aytur YK, Oztuna D, Erdogan MF. Does aerobic exercise affect the hypothalamic-pituitary-adrenal hormonal response in patients with fibromyalgia syndrome? J Phys Ther Sci 2015 Jul; 27(7):2225-31. PubMed PMID: 26311959. https://doi.org/10.1589/jpts.27.2225

9. Aschbacher K, Adam EK, Crofford LJ, Kemeny ME, Demitrack MA, Ben-Zvi A. Linking disease symptoms and subtypes with personalized systems-based phenotypes: a proof of concept study. Brain Behav Immun 2012 Oct;26(7):1047-56. PubMed PMID: 22687333. https://doi.org/10.1016/j.bbi.2012.06.002

10. Lesuis N, van Vliet J, Boers N den Broeder N, Cats H, Hulscher ME, et al. The value of routine creatine kinase and thyroid stimulating hormone testing in patients with suspected fibromyalgia: a cross-sectional study. $\begin{array}{lllll}\text { Rheumatology } 2016 \quad \text { Jul;(Oxford)55(7):1273-76. } & \text { PubMed } & \text { PMID: }\end{array}$ https://doi.org/10.1093/rheumatology/kew046

11. Nishioka K, Uchida T, Usui C, Tanaka R, Matsushima T, Matsumoto $Y$, et al. High prevalence of anti-TSH receptor antibody in fibromyalgia syndrome. Int J Rheum Dis 2017 Jun;20(6):685-90. PubMed PMID: 27905199. https://doi.org/10.1111/1756-185X.12964

12. Haliloglu S, Ekinci B, Uzkeser H Sevimli H, Carlioglu A, Macit PM. Fibromyalgia in patients with thyroid autoimmunity: prevalence and relationship with disease activity. Clin Rheumatol 2017 Jul; 36(7):1617-21. PubMed PMID: 28176037. https://doi.org/10.1007/s10067-017-3556-2

13. Gürsel $Y$, Ergin $S$, Ulus $Y$, Erdoğan MF, Yalçin P, Evcik D. Hormonal responses to exercise stress test in patients with fibromyalgia syndrome. Clin Rheumatol 2001;20(6):401-5. PubMed PMID: 11771522.

14. Mannerkorpi K, Landin-Wilhelmsen K, Larsson A Cider $\AA$, Arodell O, Bjersing JL. Acute effects of physical exercise on the serum insulin-like growth factor system in women with fibromyalgia. BMC Musculoskelet Disord 2007 Jan;18(1):37. PubMed PMID: 28122522. https://doi.org/10.1186/s12891-017-1402-y

15. Reuter E, Tafelski S, Thieme K, West $C$, Haase U, Beck L, et al. Treatment of fibromyalgia syndrome with gammahydroxybutyrate: A randomized controlled study. Schmerz. 2017 Apr;31(2):149-58. PubMed PMID: 28122522. https://doi.org/10.1007/s00482-016-0166-x

16. Weaver SA, Janal MN, Aktan N, Ottenweller JE, Natelson BH. Sex differences in plasma prolactin response to tryptophan in chronic fatigue syndrome patients with and without comorbid fibromyalgia. J Womens Health (Larchmt). 2010 May;19(5):951-8. PubMed PMID:20384451. https://doi.org/10.1089/jwh.2009.1697

17. Wolfe $F$, Smythe HA, Yunus MB, Bennett RM, Bombardier $C$, Goldenberg DL et al The American college of rheumatology 1990 criteria for the classification of fibromyalgia. Arthritis Rheum 1990 Feb;33(2):160-72. PubMed PMID: 2306288.

18. Wolfe F, Clauw DJ, Fitzcharles M, Goldenberg DL, Katz RS, Mease P, et al. The American College of Rheumatology preliminary diagnostic criteria for fibromyalgia and measurement of symptom severity. Arthritis Care Res 2010 May;62(5):600-10. PubMed PMID: 20461783. https://doi.org/10.1002/acr.20140

19. Abu-Dahab S, AbuRuz SM, Mustafa K, Sarhan Y. Validation of the Arabic version of the revised Fibromyalgia Impact Questionnaire (FIQR_A) on Jordanian females with fibromyalgia. Clin Rheumatol 2014 Mar;33(3):391-6. PubMed PMID: 23900578. https://doi.org/10.1007/s10067-013-2347-7

20. Bennett RM, Friend R, Jones KD, Han BK, Ross RL. The Revised Fibromyalgia Impact Questionnaire (FIQR): validation and psychometric properties. Arthritis Res Ther 2009;11(4):R120. PubMed PMID: 19664287. https://doi.org/10.1186/ar2783

21. Morin $C M$, Belleville $G$, Belanger $L$, Ivers $H$. The Insomnia Severity Index: psychometric indicators to determine insomnia cases and evaluate treatment response. Sleep 2011 May;34(5):601-8. PubMed PMID: 21532953. 
22. Kim J, Cho SJ, Kim WJ Yang KI, Yun CH, Chu MK. Insomnia in tension-type headache: a population-based study. J Headache Pain 2017 Sep 12;18(1):95. Ther 2009;11(4):R120. PubMed PMID: 28900887. https://doi.org/10.1186/s10194-017-0805-3

23. Sajatovic $M$, Chen $P$, Young RC. Rating scale in bipolar disorder. In:Clinical trial design challenges in mood disorders, Mauricio Tohen, Charles Bowden, Andrew A. Nierenberg and John Geddes (eds), Elseiver Inc, USA, 2015, p.105-36

24. Learmonth YC, Dlugonski D, Pilutti LA, Sandroff BM, Klaren R, Motl RW. Psychometric properties of the fatigue severity scale and the modified fatigue impact scale. J Neurol Sci 2013 Aug 15;331(1-2):102-7. PubMed PMID: 23791482. https://doi.org/10.1016/j.jns.2013.05.023

25. Maresca T, Covini E, Mato AM. Conditions, controversies and contradictions between central sensitivity syndrome and depressive disorders. Vertex 2013 Se-Oct;24(111):373-91. PubMed PMID: 24312923.

26. Cuatrecasas G, Alegre C, Fernandez-Solà J Gonzalez MJ, Garcia-Fructuoso F, Poca-Dias V, et al. Growth hormone treatment for sustained pain reduction and improvement in quality of life in severe fibromyalgia. Pain 2012 Jul;153(7):1382-9. PubMed PMID: 20631018. https://doi.org/10.1210/jc.2010-0061

27. Braverman E, Oscar-Berman M, Lohmann R, Kennedy R, Kerner M, Dushaj K, et al. Low and normal IGF-1 levels in patients with chronic medical disorders (CMD) is independent of anterior pituitary hormone deficiencies: Implications for treating IGF-1 abnormal deficiencies with CMD. J Genet Syndr Gene Ther 2013 Feb 9; 4(123). pii: 1000123. PubMed PMID: 23616929. https://doi.org/10.4172/2157-7412.1000123

28. Liu TT, Qu ZW, Ren C Gan X, Qiu CY, Hu WP. Prolactin potentiates the activity of acid-sensing ion channels in female rat primary sensory neurons. Neuropharmacology 2016 Apr;103:174-82. PubMed PMID: 26188144. https://doi.org/10.1016/j.neuropharm.2015.07.016

29. Bote ME, García JJ, Hinchado MD, Ortega E. Inflammatory/stress feedback dysregulation in women with fibromyalgia. Neuroimmunomodulation 2012;19(6):343-51. PubMed PMID: 22986514. https://doi.org/10.1159/000341664

30. Cuatrecasas Cambra G. Stress and chronic pain: An endocrine perspective. Rheumatol Clin 2009 Aug;5(Suppl 2):12-4. PubMed PMID: 21794652. https://doi.org/10.1016/j.reuma.2009.04.001

31. Doerr JM, Fischer S, Nater UM, Strahler J. Influence of stress systems and physical activity on different dimensions of fatigue in female fibromyalgia patients. J Psychosom Res 2017 Feb;93:55-61. PubMed PMID: 28107893. https://doi.org/10.1016/j.jpsychores.2016.12.005

32. Semiz EA, Hizmetli S, Semiz M, Karadağ A, Adalı M, Tuncay MS, et al Serum cortisol and dehydroepiandrosteronesulfate levels after balneotherapy and physical therapy in patients with fibromyalgia. Saudi Med J 2016 May;37(5):544-50. PubMed PMID: 27146618. https://doi.org/10.15537/smj.2016.5.1503

\author{
$\diamond \diamond \diamond \diamond \diamond \diamond \diamond$ \\ http://www.ejgm.co.uk
}

